\title{
Effectiveness of Entomopathogenic Nematodes against the African White Rice Stem Borer Maliarpha separatella Rag
}

\author{
Vincent Kega $^{1, *}$, Muo Kasina ${ }^{2}$, Florence Olubayo ${ }^{3}$, John Huria Nderitu ${ }^{3}$ \\ ${ }^{1}$ Kenya Agricultural and Livestock Research Organization, Industrial Crops Research Centre, Mwea, Kenya \\ ${ }^{2}$ Kenya Agricultural and Livestock Research Organization, National Sericulture Research Centre, Kenya \\ ${ }^{3}$ Department of Plant Science and Crop Protection, College of Agriculture and Veterinary Services, University of Nairobi, Kenya
}

Received December 23, 2019; Revised January 30, 2020; Accepted February 7, 2020

Copyright $\bigcirc 2020$ by authors, all rights reserved. Authors agree that this article remains permanently open access under the terms of the Creative Commons Attribution License 4.0 International License

\begin{abstract}
The efficacy of three entomopathogenic nematodes (EPN) species Steinernema carpocapsae Weiser, Steinernema karii Waturu, Hunt \& Reid, Heterorhabdtids indica Poinar, Karunaka \& David and two EPN isolates collected from Coastal Kenya (EX $M O M B A S A)$ and Rift valley (EX NAKURU) was evaluated against larvae of African white rice stem borer, Maliarpha separatella Rag. The experiment was carried out using no- choice modified filter paper bioassay at KARI-Mwea. Whatman filter paper was substituted with white cotton cloth discs. The activity of the biological agents under study was determined at $25^{\circ} \mathrm{C}$ and $65 \%$ relative humidity, with concentrations of 50, 100 and 200 infective juveniles (IJs) per one $M$. separatella third instar larva. The larvae were confined in $60 \mathrm{~mm}$ plastic petri dishes in darkness as the larvae spend their entire life inside the rice stems. The mortality rate was determined at 24, 48, 72 and 96 hours after application of the nematode suspension. Significant virulence was obtained with all the nematode species at 200 infective juveniles (IJs). There was low mortality at 50 and 100 concentration rates. All the EPNs significantly reduced $M$. separatella larvae after 48 hours in the following order $H$. indica $>E X$ NAKURU>S. carpocapsae> EX MOMBASA >S. karii. The number of nematodes from the infected cadavers after 48 hours post infection was $H$. indica (553), EX-MSA (294), EX-NKU (242), S. karii (168) and S. carpocapsae (157). S. karii took the longest time (96 hours) to kill all the test insects. In conclusion, the study shows that EPNs are effective against $M$. separatella and could be used within an integrated pest management strategy for the pest. There is need to carry out further studies to determine effective dosages under field conditions.
\end{abstract}

Keywords Entomopathogenic Nematodes, Efficacy,
African White Rice Stem Borer, Maliarpha separatella

\section{Introduction}

The control of pests and diseases including Maliarpha separatella at Mwea irrigation scheme is through use of pesticides following a calendar based spraying regime developed by Mwea Integrated Agricultural Development Centre (MIAD). However, use of pesticides is associated with various problems. For farmers, the most serious are the acquisition of pest resistance to the chemicals, secondary pest outbreaks, and health hazards associated with the application of chemicals. For consumers, the main problems are pesticide residues in food and environmental degradation [16]. Due to these factors, research towards developing alternative control strategies is warranted and the use of entomopathogenic nematodes (EPNs) in irrigated rice ecologies offers a viable alternative. Most of EPN formulations used in biological control of insect pests are from two Families namely Steinernematidae and Heterorhabditidae in order Rhabtida [1]. The formulations consist of third stage infective juvenile (sometimes referred to as IJ or dauer). It is non-feeding, developmentally arrested and the only EPN life stage that exists outside the host insect. The IJ seeks insect hosts, and after entering, they release an associated mutualistic bacterium, Xenorhabdus for Steinerernematids and Photorhabdus for Heterorhabditids, respectively [1]. The nematode-bacterium complex usually causes host mortality within 24- 48 hours [2]. The nematodes provide shelter to the bacteria, which, in turn, kill the insect host and provide nutrients to the nematode [1]. The bacteria 
produce pigments so that insects infected by Heterorhabtidis turn brick red or maroon colour and those infected with Steinernematids turn ochre, tan or brown [9]. All nematode-infected insect cadavers have a distinct firm and rubbery consistency, and stay intact for more than a week, while the nematodes complete their life cycle [9].

In Kenya EPNs have been used to control insect pests [14], [15], [10], [19], but none have been tested against $M$. separatella. The aim of this research was to determine the efficacy of three EPN species, Steinernema carpocapsae, Steinernema karii, Heterorhabditis indica and two strains collected from Coastal Kenya (EX MOMBASA) and from Rift valley ( $E X N A K U R U$ ), against the larvae of $M$. separatella.

\section{Materials and Methods}

The study was carried out at Kenya Agricultural Research Station, Mwea (37.36502 E, 0.62153S) entomology laboratory on 25-28 October 2010. Cultures of three entomopathogenic nematode species and two isolates were used. These were from colonies maintained in the laboratory and included S. carpocapsae, S. karii, H. indica and two EPN isolates collected from Coastal Kenya (EX MOMBASA) isolate [19] and from Rift valley (EX $N A K U R U$ ) isolate [13]. Infective juveniles (IJs) of the five isolates were cultured in the last in- star of the greater wax moth, Galleria mellonella L. at $20-22^{\circ} \mathrm{C} 60-65 \%$ relative humidity. The emerging IJs were harvested from White traps and stored in distilled water at $10^{\circ} \mathrm{C}$.

Maliarpha separatella third instar larvae were used for the assay. They were maintained on an artificial diet modified by the author at KARI-Katumani insectary. The colony had been established by collecting $M$. separatella eggs from rice fields at Mwea rice irrigation scheme and maintained on an artificial stem borer rearing diet.

The diet ingredients and procedure for diet preparation was adopted from the method Songa et al for artificial rearing of cereal stem borers [18]. Diet was modified by substituting sorghum leaf powder by rice leaf powder prepared from leaves of six weeks old rice plants which were dried and ground into a fine powder. The ingredients and the ratios used for 1.5 liter diet were: distilled water $(80.1 \%)$, Brewer's yeast $(2.3 \%)$, sorbic acid $(0.13 \%)$, methyl-p-hydroxylbenzoate $(0.2 \%)$, ascorbic acid $(0.25 \%)$, vitamin E capsules $(0.2 \%)$, rice leaf powder $(2.5 \%)$, Bean (Phaseolus vulgaris) powder (8.8\%), sucrose $(3.5 \%)$, agar (Tech No 3$)$ powder (1.3\%), formaldehyde $40 \%(0.2 \%)$. and Grabacin $(0.2 \%)$.

Maliarpha separatella larvae collected from infested rice fields were then introduced into diet at the rate 20 larvae per jar, where they developed up to adult moth emergence. The emerging moths were sexed and five pairs introduced into oviposition cages which were lined with wax paper. The female moths laid eggs on the wax paper. The sections of the wax paper with eggs were then cut out, put in sterilized Sterlin ${ }^{\circledR}$ plastic petridishes and incubated at $30^{\circ} \mathrm{C}$ for $24 \mathrm{hrs}$ up to black head egg stage. The black heads were surface sterilized by $70 \%$ ethanol and introduced into the artificial rearing diet. They were then allowed to develop into $3^{\text {rd }}$ instar larvae and used in the bioassay.

\section{Entomopathogenic Nematodes Evaluation}

Contact filter paper bioassays against Maliarpha separatella using the five entomopathogenic nematodes isolates were set up at KARI-Mwea entomology laboratory. Standard filter paper bioassays have been used before to evaluate EPNs [20] but in the present study white cotton cloth discs were used instead of the Whatman ${ }^{\circledR}$ filter paper.

Suspensions of EPNs were first agitated by blowing into the suspension by a pipette and the equivalent aliquots of nematode concentrations were drawn.

Treatments consisted of three concentrations of entomopathogenic nematodes (EPN), 50, 100 and $200 \mathrm{IJs}$ and an untreated control. One $\mathrm{ml}$ of nematode suspension was added to each Sterlin ${ }^{\circledR} 60 \mathrm{~mm}$ plastic petridish containing a folded cotton cloth disc using a pipette, with the tip being changed after every treatment. In the control treatments $1 \mathrm{ml}$ of distilled water without nematodes was added to the cotton cloth discs. One M. separatella $3^{\text {rd }}$ instar larva was then introduced on top of cloth disc which was already moist with the nematode suspension making sure that the larvae did not drown. They were closed and incubated at temperatures of $25^{\circ} \mathrm{C} \pm 2^{0}$ and $65-75 \%$ relative humidity. The experiment was laid out in a completely randomized design with 10 replicates for each nematode isolate at the test concentrations. Observations were done on 24, 48, 72 and 96 hours after M. separatella larva introduction. On each of these observations mortality was measured and M. separatella cadavers observed for firm rubbery consistency and colour change (brick red or maroon colour for Heterorhabtidis and ochre, tan or brown for Steinernematids [9] which indicate nematode infectivity. They were then put in $1 \%$ Ringer's salt solution and dissected under a binocular microscope in an engraved Petri dish. The number of first generation nematodes was counted using a tally counter under low power binocular microscope. Analysis of variance (ANOVA) was conducted to determine the differences in mortality rates. Least significant differences were used to separate means when found significant at $p=0.05$. The statistical analysis was performed using Genstat Version 12 statistical software [7]. Probit regression analysis was performed on the data to estimate effective concentration and lethal periods following the method of Finney [6]. 


\section{Results}

Probit curve showed Heteterorhabitidis indica as the EPN requiring the least concentration to cause $100 \% \mathrm{M}$. separatella mortality while $S$. karii, $S$. carpocapsae and $E X M O M B A S A$ required slightly higher than $200 \mathrm{IJ}$ to kill all the test insects. The order of virulence was $H$. indica $>\quad E X \quad N A K U R U>\quad S$. carpocapsae $>\quad E X$ $M O M B A S A>S$. karii (Fig 1)

All EPNs were effective against $M$. separatella within 48 hours of infection. EX-NAKURU had the earliest median LT50, while $S$. karii took the longest time to kill all the test insects (Figure 2)

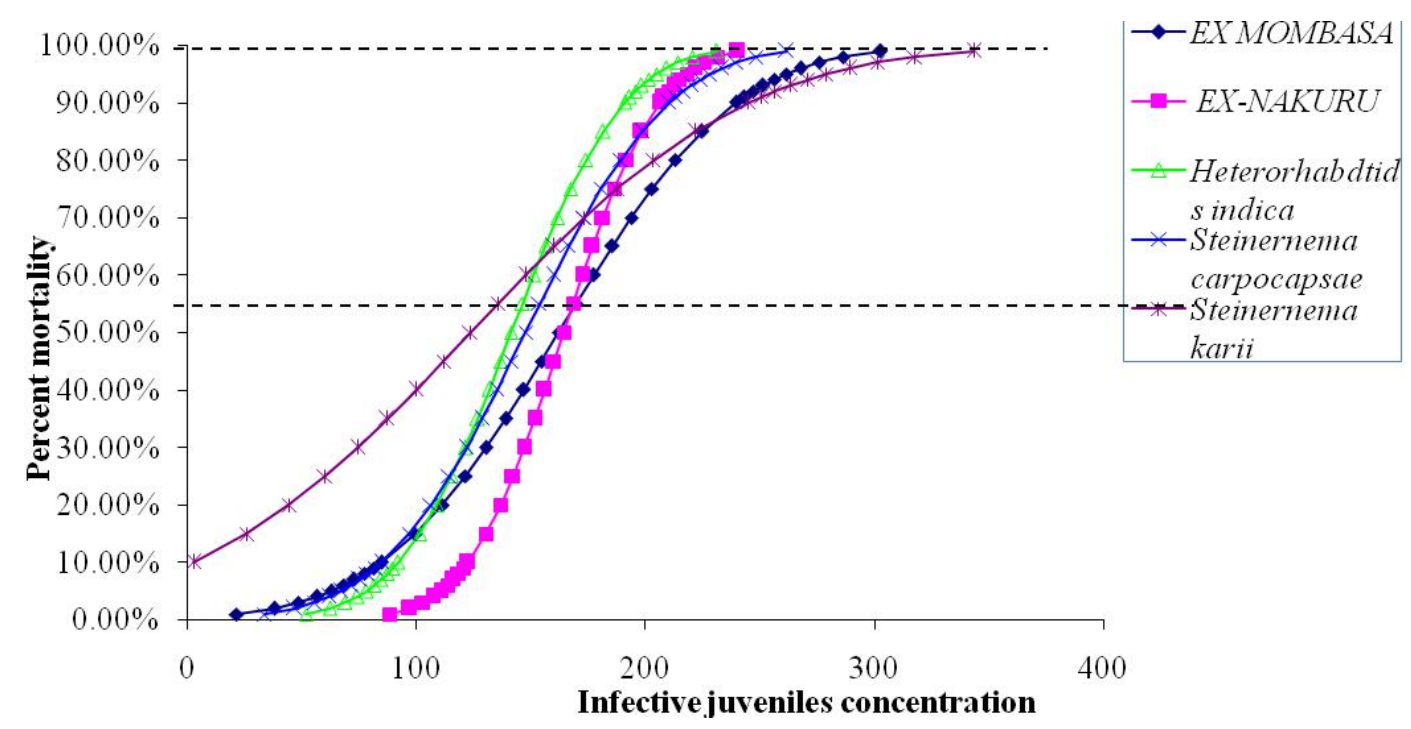

Figure 1. Median lethal concentration $\left(\mathrm{LC}_{50}\right)$ and $\mathrm{LC}_{90}$ of different $\mathrm{EPN}$ isolates to M. separatella larvae.

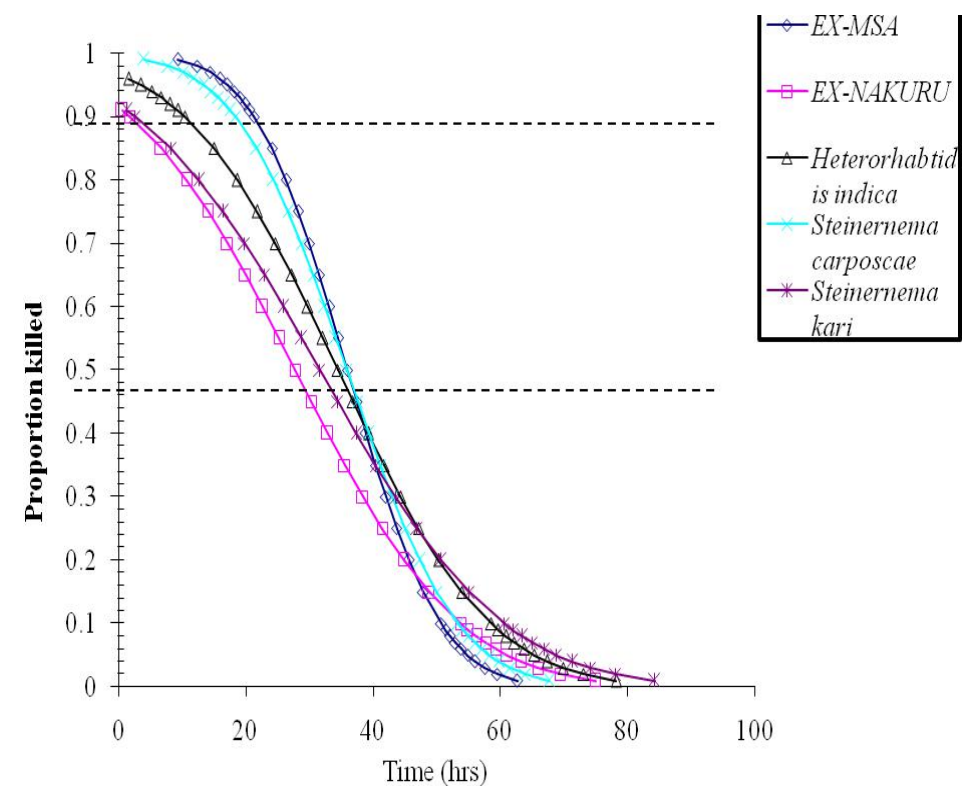

Figure 2. Median lethal time (LT 50) and LT 90 of M. separatella larva after infection by different EPN isolates 
Heterorhabtidis indica had the highest number of first generation EPNs in M. separatella cadavers after 48 hours post infection followed by EX-MSA, while the least number of EPNs was in Steinernema carpocapsae (Table $1)$.

Table 1. The mean number of first generation Entomopathogenic nematodes in M. separatella host cadavers after 48 hours post infection.

\begin{tabular}{|l|l|}
\hline Isolate & $\begin{array}{l}\text { Number of EPNs per M. separatella } \\
\text { cadaver (Mean } \pm \text { SE) }\end{array}$ \\
\hline $\begin{array}{l}\text { Steinernema } \\
\text { carpocapsae }\end{array}$ & $157.23 \pm 0.64$ \\
\hline Steinernema karii & $168.19 \pm 0.81$ \\
\hline $\begin{array}{l}\text { Heterorhabdtidis } \\
\text { indica }\end{array}$ & $552.93 \pm 0.74$ \\
\hline EX-NKU & $242.00 \pm 0.90$ \\
\hline EX-MSA & $293.56 \pm 0.66$ \\
\hline $\mathrm{P}$ & 0.33 \\
\hline CV (\%) & 48.7 \\
\hline
\end{tabular}

\section{Discussion}

The results of this study indicated that Heterorhabtidis indica nematode was effective against the African white rice stem borer $M$. separatella at higher concentrations (200 IJs/larva) and caused host mortality within 24 to 48 hours after infection. These results are in agreement with most studies on EPNs which indicate that they kill insect pests within one to two days [4]. There were significant differences in infectivity among the test entomopathogenic isolates. These results are consistent with the findings of Ellis and co-authors who found from screening bioassays of 10 nematode isolates against small hive beetle, Aethina tumida that nematode efficacy varied significantly among the tested nematode species [5]. The efficacy was also affected by the number of the applied infective juveniles (IJs). Nyasani and co-workers found significant differences in the efficacy of different entomopathogenic nematodes against diamond back moth [15]. Past studies indicate that EPNs are effective when well matched with host arthropod pests [8] and that different species of entomopathogenic nematodes vary in the range of the insects they attack and their environmental needs[17]. The high mortality caused by $H$. indica which also had the highest multiplication rate in $M$. separatella host cadavers is in agreement with the findings of Shapiro-Ilan and Gaugler who demonstrated that invasion and reproduction in hosts by different nematode species varied quantitatively [17]. Menti and co-workers reported that Heterorhabditis spp often infect at lower rates than Steinernema spp but comparative mortality is often similar or higher as was found out in this study [12]. The discrepancy in infectivity between
Heterorhabditids and Steinernematids may be attributed to differences in the time of establishment of the symbiotic bacteria in the insect host.

The most effective entompathogenic nematode was $H$. indica. It is heat tolerant, infecting insects at $30^{\circ} \mathrm{C}$ or higher. The nematode produces high yields in vivo and in vitro, but shelf life is generally shorter than most of the other nematode species. Nderitu and co-workers also found this EPN to have significant efficacy against Cylas puncticollis in sweet potato fields at Kibwezi in Kenya [14]. Similarly, Mahar and others in a study to control nymphs of desert locust Schistocerca gregaria found that Heterorhabditids ( $H$. indica and H. bacteriophora) were more effective as compared to Steinernematids ( $S$. carpocapsae, $S$. feltiae) at 30 degrees centigrade [11] and that the highest concentration of each isolate (200 IJs per $\mathrm{ml}$ ) proved to be most appropriate for maximum insect death. In the current study most of the nematodes had high chances of penetrating the host and this is supported by reports by Declan and co-authors who when screening $S$. feltiae and $S$. carpocapsae against Plectrodera scalator reported that filter paper bioassays killed $50-58 \%$ of larvae but the mortality in diet cup bioassay was less than $10 \%[3]$.

The period of exposure and concentration were important factors for the activity of the nematodes. This can possibly be explained by the fact that the number of EPNs penetrating the host is influenced by the number of invasive nematodes which earlier managed to penetrate it. The results of this research show that application of entomopathogenic nematodes is a possible way for controlling M. separatella but there is need to optimize environmental factors to improve efficacy under field conditions.

\section{Conclusions}

- Heterorhabtidis indica caused the highest mortality and also had the highest multiplication rate in $M$. separatella host cadavers.

- Application of Heterorhabtidis indica was able to control M. separatella

- Heterorhabdtids indica nematode was effective against African white rice stem borer Maliarpha separatella at higher concentrations (200 IJs/larva) and was heat tolerant, infecting insects at $30^{\circ} \mathrm{C}$ or higher

\section{Recommendations}

Heterorhabdtids indica which was the species with the highest number of penetrated nematodes in host cadavers can be used for M. separatella management. However, there is need to optimize environmental factors and use the most appropriate method for application of this species 
under field conditions.

\section{Acknowledgements}

This study was co- funded by National Council for Science, Technology and innovations (NACOSTI) formerly the National Council for Science and Technology (NCST) under the $2^{\text {nd }}$ Call for competitive grants for Doctorate/ Master of Science students and Director General Kenya Agricultural and Livestock Research organization (KALRO) which was previously Kenya Agricultural Research Institute (KARI) under the Kenya Agricultural and Agri-business Productivity Project (KAAPP).

\section{REFERENCES}

[1] Adams, B. J. and Nguyen, K. B. 2002. Taxonomy and Systematics: General biology. In. Entomopathogenic Nematology (ed. R. Gaugler) CABI Publishing, CAB International: 1-2.

[2] Burnel, A and Stock, S.P 2000. Heterorhabditis, Steinernema and their bacterial symbionts-Lethal pathogens of insects, Nematology 2(1), 31-42

[3] Declan, J.F., Leellen, F.S., Leah, S.B., Deborah, L.M., James, R.C. and Michael, L.M. (2006). Effect of entomopathogenic nematodes on Plectrodera scalator (Fabricius) (Coleoptera: Cerambycidae). Journal of Invertebrate Pathology. 92 (2006):55-57

[4] Divya, K., Sankarb, M., and Marulasiddesha, K.N. 2010 Efficacy of Entomopathogenic Nematode, Heterorhabditis indica against three lepidopteran insect pests. Asian Journal of Experimental Biology and Science (1, 1): 183-188.

[5] Ellis, J.D, Spiewok, S., Delaplane, K., Buchholz, S., Neumann, P., and Tedders, W. 2010. Susceptibility of Aethina tumida (Coleoptera: Nitidulidae) larvae and pupae to entomopathogenic nematodes. Journal Econonmic Entomology 103(1): 1-9.

[6] Finney, D.J. 1971. Probit analysis 3rd edition Cambridge University Press, Cambridge, U.K

[7] GENSTAT, (2009). Genstat statistical package for windows version 12.0 .

[8] Gaugler, R. (1999). Matching nematodes and insects to achieve optimal field performance. Optimal Use of Insecticidal Nematodes in Pest Management Workshop Proceedings: 9-14. Edited by S. Polavarapu, Rutgers University

[9] Greenwood, C. M. and Rebek, E. J. (2008). Detection, Conservation, and Augmentation of Naturally Occurring Beneficial Nematodes for Natural Pest Suppression. Oklahoma Cooperative Extension Fact Sheets, Oklahoma Cooperative Extension Service EPP-7670, 6http://osufacts.okstate.edu. Accessed on 5 July 2012.
[10] KARI, (2006). Field evaluation of entomopathogenic nematodes for efficacy against cotton pests. Kenya Agricultural Research Institute 2006 Annual Report: 85-86.

[11] Mahar, A. N., Jan, N. D., Gowen, S. R., Hague, N. G. M., Al-Siyabi, A. A. , Mahar, A. Q. (2006). A comparative study on the effectiveness of laboratory bioassays of entomopathogenic nematodes against desert locust nymphs Schistocerca gregaria (Acrididae:Orthoptera). Pakistan Journal of Nematology 24: 151-161.

[12] Menti, H., Wright, D.J., Perry, R.N., (2000). Infectivity of populations of the entomopathogenic nematodes Steinernema feltiae and Heterorhabditis megidis in relation to temperature, age, and lipid content. Nematology 2: $515-521$.

[13] Mwaniki, S.W., Nderitu, J.H., Olubayo, F., Kimenju, J.W., and Nguyen, K. (2008). Factors influencing the occurrence of entomopathogenic nematodes in the Central Rift Valley region of Kenya. African Journal of Ecology 46: 79-84.

[14] Nderitu, J. Sila, M. Nyamasyo, G. and Kasina, M. (2009). Effectiveness of Entomopathogenic Nematodes against Sweet Potato Weevil (Cylas puncticollis Boheman (Coleoptera: Apionidae)] under semi-field Conditions in Kenya. Journal of Entomology 6: 145-154.

[15] Nyasani, J.O., Kimenju, J.W., Olubayo, F.M., Shibairo S.I. and Mutua G.K. (2008). Occurrence of entomopathogenic nematodes and their potential in the management of Diamond Back Moth in kale. Asian journal of plant sciences 7(3): 314-318.

[16] Ooi, P. A. C, (2005). Some Non-Pesticide Methods for Managing Crop Insect Pests- Present Status, Issues and Strategies. Non pesticide Methods for Controlling Diseases and Insect Pests. Report of the APO Seminar on Non pesticide Methods for Controlling Diseases and Insect Pests held in Tokyo, Japan, 10-17 April 2002 (Eds Ooi, P.A.C) Asian Productivity Organization (APO) ISBN: 92-833-7037-6: 15-24.

[17] Shapiro-Ilan, D.I., and Gaugler, R. (2010). Nematodes: Rhabditida: Steinernematidae \& Heterorhabditidae. In: Biological Control: A Guide to Natural Enemies in North America. Edited by A. Shelton, Cornell University. http://www.biocontrol.entomology.cornell.edu/pathogens/ nematodes.html. Accessed 26 July 2012.

[18] Songa, J.M., Bergvinson, D. and Mugo, S. (2001). Mass rearing of the maize stem borers Chilo partellus, Busseola fusca, Sesamia calamistis, Chilo orichalcociliellus and Eldana saccharina KARI-Katumani. In proceedings of Seventh Eastern and Southern Africa Regional maize conference 12-15 February 2001: 120-124.

[19] Waturu, C.N. (1998). Entomopathogenic Nematodes (Steinernematidae and Heterorhabditidae) from Kenya, PhD thesis, University of Reading 191pp.

[20] Woodring, J. L., and Kaya, H. K. (1988). Steinernematid and Heterorhabditid nematodes: handbook of biology and techniques. Southern Cooperative Series Bulletin 331. A publication of the nematode subcommittee of the Southern Research Project S135- Entomopathogens for use in Pest Management Systems. Arkansas Agricultural Experiment Station, Fayetteville, AR. [2,887 words] 